San Jose State University

SJSU ScholarWorks

Master's Theses

Master's Theses and Graduate Research

1995

\title{
An assessment of genetic variation within and between sea otter (Enhydra lutris) populations off Alaska and California
}

Lisa Christine Cheney

San Jose State University

Follow this and additional works at: https://scholarworks.sjsu.edu/etd_theses

\section{Recommended Citation}

Cheney, Lisa Christine, "An assessment of genetic variation within and between sea otter (Enhydra lutris) populations off Alaska and California" (1995). Master's Theses. 1053.

DOI: https://doi.org/10.31979/etd.d2qk-9pup

https://scholarworks.sjsu.edu/etd_theses/1053

This Thesis is brought to you for free and open access by the Master's Theses and Graduate Research at SJSU ScholarWorks. It has been accepted for inclusion in Master's Theses by an authorized administrator of SJSU ScholarWorks. For more information, please contact scholarworks@sjsu.edu. 


\section{INFORMATION TO USERS}

This manuscript has been reproduced from the microfilm master. UMI films the text directly from the original or copy submitted. Thus, some thesis and dissertation copies are in typewriter face, while others may be from any type of computer printer.

The quality of this reproduction is dependent upon the quality of the copy submitted. Broken or indistinct print, colored or poor quality illustrations and photographs, print bleedthrough, substandard margins, and improper alignment can adversely affect reproduction.

In the unlikely, event that the author did not send UMI a complete manuscript and there are missing pages, these will be noted. Also, if unauthorized copyright material had to be removed, a note will indicate the deletion.

Oversize materials (e.g., maps, drawings, charts) are reproduced by sectioning the original, beginning at the upper left-hand corner and contimuing from left to right in equal sections with small overlaps. Each original is also photographed in one exposure and is included in reduced form at the back of the book.

Photographs included in the original manuscript have been reproduced xerographically in this copy. Higher quality $6^{n} \times 9^{n}$ black and white photographic prints are available for any photographs or illustrations appearing in this copy for an additional charge. Contact UMI directly to order.

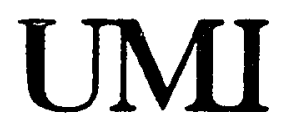

A Bell \& Howell information Company 300 North Zeeb Road. Ann Arbor. MI 48106-1346 USA 313:761-4700 800:521-0600 

AN ASSESSMENT OF GENETIC VARIATION

WITHIN AND BETWEEN SEA OTTER (ENHYDRA LUTRIS)

POPULATIONS OFF ALASKA AND CALIFORNIA

\author{
A Thesis \\ Presented to \\ The Faculty of Moss Landing Marine Laboratories
}

\author{
In Partial Fulfillment \\ of the Requirements for the Degree \\ Master of Science
}

by

Lisa Christine Cheney

August, 1995 
UMI Number: 1375677

UMI Microform 1375677

Copyright 1995, by UMI Company. All rights reserved.

This microform edition is protected against unauthorized copying under Title 17, United States code.

\section{UMI}

300 North Zeeb Road

Ann Arbor, MI 48103 
(C)1995

Lisa Christine Cheney

ALL RIGHTS RESERVED 
APPROVED FOR THE DEPARTMENT OF BIOLOGY

Cames i Alavey

Dr. James T. Harvey, Moss Landing Marine Laboratories

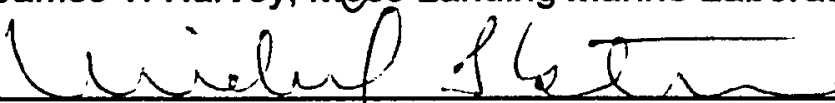

Br. Michael Fostêk, Moss Landing Marine Laboratories

Suber \&

Dr. Robert K. Wayne, Yniversity of California, Los Angeles

APPROVED FOR THE UNIVERSITY

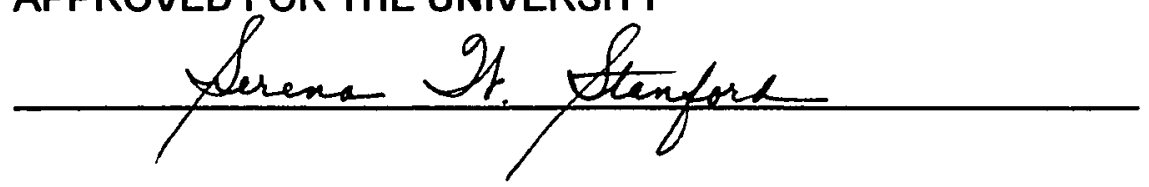




\begin{abstract}
AN ASSESSMENT OF GENETIC VARIATION

WITHIN AND BETWEEN SEA OTTER (ENHYDRA LUTRIS)

POPULATIONS OFF ALASKA AND CALIFORNIA
\end{abstract}

by Lisa Christine Cheney

Nucleotide sequences of the mitochondrial DNA (mtDNA) control region of sea otters (Enhydra lutris) from California and Alaska were analyzed to determine if these populations are genetically distinct. Four haplotypes were found, two being unique to each population. Nucleotide sequence divergence values were calculated as $0.3 \%$ for California, $0.6 \%$ for Alaska, and $0.3-0.6 \%$ between populations. Relatively low genetic variation in these populations may be attributed to: severity of bottleneck during past population reduction, low genetic variation in the historical population, or constraint in the evolution of the mtDNA D-loop in mustelids. Low levels of variability and geographically different haplotypes indicate that the two populations should be designated as separate evolutionary significant units (e.s.u.). The California population of sea otters should receive increased monitoring because of its low nucleotide divergence values, small population size, and slow recovery rate. 


\section{ACKNOWLEDGMENTS}

I would like to thank my committee members, Dr. James T. Harvey, Dr. Michael S. Foster and Dr. Robert K. Wayne for their encouragement, guidance and helpful comments on this manuscript.

This work could not have been completed without the invaluable assistance and collaboration of Klaus Koepfli, Dr. Robert K. Wayne and everyone at the UCLA Evolutionary Genetics Laboratory. I am grateful to J. Maldonado and D. Girman for technical assistance, encouragement and valuable advice.

I thank my parents, Normand $\mathrm{O}$. Caron and Christine L. Caron for allowing me to take the road less traveled by-it has worn me well. I thank them also for instilling in me the confidence and the courage to pursue my goals.

I am indebtted to F. Rofougaran for providing me with lodging, friendship and laughter during my stay in Los Angeles. I also thank J. Parkin and L. OsnesErie for their valued friendships and for reviewing this manuscript.

I thank my husband Randy Cheney for his unfailing patience and support. I also thank S.O'Brien, J. Bodkin and the Monterey Bay Aquarium for providing blood samples. Research grants from the Earl and Ethel Meyers Oceanographic Trust Fund, the David and Lucille Packard Foundation, and the American Cetacean Society, Monterey Bay Chapter helped to make this research possible.

Finally, I thank the MLML students, faculty and staff for providing me with a learning experience and friendships that I will treasure for years to come long after I leave. . 


\section{TABLE OF CONTENTS}

Abstract

Acknowledgments

Table of Contents

List of Tables

List of Figures

Introduction

Materials and Methods

Sample collection and DNA extraction

Polymerase chain reaction (PCR)

Single-stranded conformation polymorphism (SSCP-PCR)

Sequencing

Analyses

Results

Discussion

Literature Cited

Tables

Figures

Appendices

(A) Geneclean protocol

(B) Double-stranded sequencing protocol
Pages

iv

V

vi

vii

viii

$1-5$

$6-10$

6

7

$7-8$

8-9

$9-10$

$11-13$

$14-24$

25-31

$32-34$

$35-41$

42-44

42

$43-44$ 


\section{LIST OF TABLES}

Table

Page

1. Frequency of sea otter mitochondrial DNA control region sequence haplotypes by geographic locality.

2. Mean nucleotide sequence divergence and absolute distances among sea otter haplotypes.

3. Marine mammal mtDNA nucleotide sequence divergence values. 


\section{LIST OF FIGURES}

Figure Page

$\begin{array}{ll}\text { Figure captions } & 38\end{array}$

1. California sea otter population size over time. 39

2. Geographic location of sea otter sampling sites. 40

3. Single-stranded conformation polymorphism-PCR sequencing gel 41 autoradiograph.

4. (A) Adequacy of sample size for Alaska sea otter population. 42

(B) Adequacy of sample size for California sea otter population. 42

5. List of sea otter mtDNA D-loop sequences. 43

6. Sample autoradiograph of sea otter mtDNA sequences. 44

7. Network of sea otter mtDNA haplotypes. 45

8. Autoradiograph of sea otter microsatellites at Llu3/252 locus. 46 


\section{INTRODUCTION}

Populations of the sea otter (Enhydra lutris) off Alaska and California have undergone dynamic changes during the past several centuries. In the mid1700 s, these two populations were part of a continuous range that extended from the central west coast of Baja, California, north to Alaska, throughout the Aleutian Islands westward to Kamchatka, Russia, and south to the Kuriles (Miller 1974). During the eighteenth century, the sea otter population off California was an estimated 16,000 to 18,000 individuals (California Dept. of Fish and Game 1976; U.S. Fish and Wildlife Service 1982; Riedman and Estes 1990), whereas the population off Alaska was in excess of 100,000 individuals (Miller 1974; Lensink 1975; Woolfenden 1985). Overexploitation of the sea otter by fur hunters from the mid-eighteenth to the early twentieth century severely reduced and subdivided this continuous population into small isolated groups (Riedman and Estes 1990). By the early 1900s, the remnant population off California was possibly 30 to 50 individuals, whereas the remaining Alaska population was approximately 300 individuals (Miller 1974; Woolfenden 1985).

Both sea otter populations have since expanded in number and range. The Alaska population of sea otters has fully recovered to its original size, whereas the California population estimate in 1994 was 2500 animals (California Dept. of Fish and Game 1994, Fig.1). Subpopulations have increased 17 to $20 \%$ per year for newly colonized areas in Alaska and 4 to $5 \%$ per year off California (Estes 1980; Riedman and Estes 1990). Given the low number of founding individuals and slow recovery rate of the California population, it appears that the bottleneck was more severe in this population than in the Alaska population. $A$ 
bottleneck refers to when a large population passes through a contracted stage followed by an expansion. Usually this phenomenon is associated with a change in genetic composition as a result of genetic drift (Hoelzel and Dover 1991).

The limited recovery in the California population may be caused by decreased prey availability, predation, pollution, or low genetic variability. Decreased prey availability seems an unlikely cause for limited recovery, because sea otters can alter their diet based on prey abundance (Ebert 1968; Ostfeld 1982). Predation by white shark (Carcharodon carcharias) and killer whales (Orcinus orca) are rare events that probably would not have an observable effect on population numbers (Kenyon 1969). In past studies, pollution in the form of PCB, DDT, and heavy metals, had no significant effect on sea otters (Shaw 1971; Rote 1976). Currently, concentrations of DDT are 5 to 250 times greater in sea otters off California compared with sea otter subpopulations off Alaska (Bacon 1993).

Reduced genetic variation may be a factor influencing the relatively slow growth rate of the California population of sea otters. Variation within a population may reflect the relative fitness of a group. Bottleneck and founder events often increase inbreeding, consequently decreasing heterozygosity, fitness, viability, and growth rates. These factors act to form a more homogeneous gene pool that as a result is more susceptible to dynamic changes in the environment. The severity of a bottleneck event often correlates directly with reduced fitness of a population (Frankel and Soule 1981; Ralls and Ballou 1983; Allenderf 1986; Ralls et al. 1988; Quattro and Vrijenhoek 1989). Levels of genetic variation also may be used to examine trends of population differentiation. For example, a number of behavioral and morphological 
differences exist between the Alaska and California populations of sea otters. These differences may be simply due to adaptation to varied habitats, or may reflect a degree of genetic differentiation.

The two populations of sea otters differ in morphology, feeding ecology, and reproductive and social behavior. Based on skeletal characters, these populations have been designated as distinct subspecies. In the past, the Alaska population was identified as Enhydra lutris nereis and the California population as Enhydra lutris lutris (Roest 1971; Davis and Lidicker 1975). Wilson et al. (1991) recently proposed the same subspecies based on skeletal morphology. However, they classified the California population as Enhydra lutris nereis and the Alaska population as Enhydra lutris kenyoni. Sea otters off Alaska typically are 8 to $9 \%$ longer and weigh 27 to $36 \%$ more than sea otters off California (Ames et al. 1983; Riedman 1987).

The feeding ecology of sea otters between these populations differs slightly. Sea otters off Alaska typically forage to greater depths and on a greater variety of prey types than sea otters off California (Boolootian 1961; Limbaugh 1961; Barabash-Nikiforov 1962; Wild and Ames 1974; Estes 1980; Estes et al. 1981; Ostfeld 1982; Riedman and Estes 1988). Tool use is rare in the Alaska population but is common among sea otters off California (Fisher 1939; Kenyon 1969).

Reproductive behavior is similar between sea otters off Alaska and California. Sea otters of both populations mate and pup throughout the year. Off California, pupping peaks from January to March with a secondary peak occurring in late summer to early fall (Fisher 1940; Vandevere 1970; 1972; Sandegren et al. 1973, Estes and Jameson 1983, Siniff and Ralls 1988). Off 
Alaska, timing of reproduction is more synchronized and occurs two to three months later than off California (Kenyon 1969). In the California population, copulation may occur with or without the formation of a pair bond, whereas off Alaska, pair bonds occur more frequently (Vandevere 1970; Schneider 1972).

Sea otters off California and Alaska exhibit sexual segregation, although this behavior is more prominent off Alaska. Males off Alaska typically reside further offshore in areas of greatest food abundance, whereas females use sheltered nearshore regions. Male and female sea otters off Alaska exhibit larger home ranges than sea otters off California (Schneider 1973; Garshelis et al. 1984; Garshelis and Garshelis 1984).

Several genetic studies of sea otters have been conducted. Rotterman (1992) examined allozymes in sea otters from central California, Prince William Sound, the Kodiak archipelago, and False Pass at Unimak Island, Alaska. She found $\mathbf{3 8}$ of $\mathbf{4 1}$ loci were monomorphic in all four subpopulations. Among sea otter subpopulations off Alaska and California, genetic distance was calculated as 0.001-0.006, indicating a high degree of similarity among these groups. Sanchez (1992) examined restriction fragment length polymorphisms (RFLPS) of the mtDNA genome in sea otter populations from the Kuril Islands, Prince William Sound, and California. She found eight haplotypes (i.e., the characteristic genetic structure of an individual derived from mtDNA), four only within the California population and two unique to the Alaskan population. This result indicated that some degree of genetic differentiation exists between these populations. Ralls et al. (1983) theorized that the current California population of sea otters should retain $77 \%$ of the genetic diversity of the historical population. This may be an overestimate, however, because they assumed constant 
population growth rate, random breeding, non-overlapping generations, and a lack of selection and mutation effects.

To examine the genetic variation of sea otters, I determined the sequence of the control region of mitochondrial DNA. The mitochondrial genor:e is an appropriate characteristic for assessing variability because it evolves rapidly and exhibits extensive polymorphism, especially within populations and closely related species (Avise 1992; 1994). Direct sequencing of the mitochondrial genome is preferred over simple restriction site analysis because greater resolution and more comprehensive information is obtained.

The working hypotheses under investigation were as follows: (1) there are significant levels of genetic variation within the California and Alaska populations of sea otters, based on the assumption that founding individuals were genetically variable (Ralls et al. 1983), and (2) there is a significant level of genetic divergence between the California and Alaska populations of sea otters, because of the number of ecological differences between the two populations, and the varying degrees of population bottleneck endured by them.

Furthermore, I hypothesized that geographic isolation has existed long enough for effective genetic differentiation of these groups.

Significant levels of genetic variation and divergence are defined here as a population that possesses four or more haplotypes per 10 individuals, and is characterized by a nucleotide sequence divergence level of $1.7 \%$ or greater. The criteria for statistical significance was derived from genetic variation values from studies of other marine mammals including California sea lions (Zalophus californianus), common dolphins (Delphinus delphis), northern (Mirounga angustirostris) and southern elephant seals (M. leonina), spotted (Stenella 
attenuata) and spinner dolphins (S. longirostris), and humpback whales (Megaptera novaeangliae) (Baker et al. 1990, Dizon et al. 1991; Hoelzel et al. 1993; Rosel et al 1994, Maldonado et al. 1995). The significance level for the number of haplotypes was determined by the median value of the number of haplotypes per sample size. The significance level of nucleotide sequence divergence was determined by using the average interpopulation divergence values from California sea lions, killer whales, and humpback whales (Baker et al. 1990, Hoelzel and Dover 1991; Maldonado et al. 1995). The value of $1.7 \%$ represents the average nucleotide sequence divergence in these marine mammal populations. These criteria were derived from marine mammal data instead of mustelid data because no published sequences exist for this family. 


\section{MATERIALS AND METHODS}

\section{Sample Collection and DNA Extraction}

Whole blood samples for genetic analyses were obtained from 75 wild sea otters in 1991 and 1992 by the California Department of Fish and Game and the U.S. Fish and Wildlife Service. These samples were collected from four subpopulations in Alaska: at Attu Island $(n=8)$, Amchitka Island $(n=8)$, Adak Island $(n=8)$ and Prince William Sound $(n=28)$, and from central California south of Big Sur ( $n=23 ;$ Fig. 2). An additional four blood samples were obtained from captive California sea otters at the Monterey Bay Aquarium. A final sample was obtained from a dead stranding in Monterey Bay, to bring the total to 80 samples. Blood samples were stored at $-70^{\circ} \mathrm{C}$.

To extract DNA from blood samples, $500 \mu l$ of blood was combined with an equal volume of $1 \times$ TNE buffer, $50 \mu$ l of $10 \%$ sodium dodecyl sulfate (SDS), and proteinase $\mathrm{K}$, spun, and incubated overnight at $55^{\circ} \mathrm{C}$. Total genomic DNA was isolated from white blood cells separated from whole blood by equal volume washes (500 $\mu$ leach) of buffered phenol, phenol-chloroform-isoamyl (25:24:1), and chloroform-isoamyl (24:1), followed by ethanol precipitation. DNA was resuspended in a volume of Tris-EDTA (TE) buffer to a final concentration of approximately $1-2 \mu \mathrm{g} / \mu \mathrm{l}$, and stored at $-20^{\circ} \mathrm{C}$ (Sambrook et al. 1989). 
Polymerase Chain Reaction (PCR)

A 394 basepair (bp) portion of the control region was amplified using the universal primers L15926: 5'-GA-ATTCCCCGGTCTTGTAAACC-3" and H16340: 5'-CCTGAAGTAGGAACCAGATG-3"; modified from Kocher et al. (1989). Polymerase chain reaction mixtures each contained approximately $100 \mathrm{ng}$ genomic DNA, 25 pmoles of each primer, $1 \mathrm{mM}$ of each dNTP, $50 \mathrm{mM} \mathrm{KCl}, 2.5$ $\mathrm{mM} \mathrm{MgCl}$, and 2.5 units Taq polymerase. DNA strands were amplified in a Perkin-Elmer Cetus DNA thermal cycler via the following profile: denaturation $30 \mathrm{sec}$. at $94^{\circ} \mathrm{C}$, annealing $35 \mathrm{sec}$. at $55^{\circ} \mathrm{C}$, and extension $45 \mathrm{sec}$. at $72^{\circ} \mathrm{C}$ for 30 cycles. An additional extension period of seven min. at $72^{\circ} \mathrm{C}$ followed the cycling profile. Products were stored at $4^{\circ} \mathrm{C}$.

Twelve samples that did not yield products by this PCR program were amplified using the hot start technique (M. Roy, pers. comm.). This technique provided for maximum denaturation of DNA fragments, thereby increasing overall product yield. Maximum denaturation of DNA was achieved by heating the pcr mixtures without the Taq polymerase, at $94^{\circ} \mathrm{C}$ for $5 \mathrm{~min}$. before the standard PCR cycle. This ensures that all DNA strands are denatured before the Taq polymerase can catalyze nucleotide binding to the template sequence. At the end of this extended denaturation period, 2.5 units of Taq polymerase were added to each tube. The thermal profile was then resumed. 
Single stranded conformation polymorphism-PCR (SSCP-PCR)

Single stranded conformation polymorphism-PCR was used as a means of simple, rapid identification of sample haplotypes. This method was initially attempted using samples of known haplotypes to determine if genotypes could be discerned by sequence motility in a polyacrylamide gel. The technique was successful in differentiating between California haplotypes. However, sequence differences of the Alaska samples were not distinguishable on the gel (Fig. 3).

$\mathrm{D}$-loop primers were labeled with a $\mathrm{P}^{32}$ radioisotope using a kinase reaction. Each reaction mixture contained 400 pmoles of each primer, $2.5 \mu \mathrm{l}$ each of $10 \times$ kinase reaction buffer, P32, $0.2 \mu$ l diluted kinase (1:3 of kinase to kinase dilution buffer), and $3.8 \mu$ sterile water to make a final volume of $25 \mu \mathrm{l}$. Kinase mixtures were incubated at $37^{\circ} \mathrm{C}$ for one $\mathrm{hr}$., then heat shocked at $94^{\circ} \mathrm{C}$ for three min, followed by immersion in wet ice.

Samples were amplified under standard conditions. Each PCR mixture contained $2.5 \mu \mathrm{l} 10 \times$ reaction buffer, $2.5 \mathrm{mM} \mathrm{MgCl}, 299 \mathrm{mM}$ dNTPs, 25 pmoles of each endlabeled primer, $1 \mu$ genomic DNA, and sterile water to a $25 \mu \mathrm{l}$ total volume. The same thermal cycle profile program was used as in the standard PCR amplification. Samples were combined with stop solution (1:9), heated at $84^{\circ} \mathrm{C}$ for five min., and then separated on a low melting point denaturing gel at 40W for $3.5 \mathrm{hrs}$. Samples were differentiated based on mobility of each strand in the gel. Positive identification of unknown samples (i.e. those with unidentified haplotypes) was made based on comparison to samples of known genotype. To ensure proper identification, positives were checked on two separate gels (Orita et al. 1989). 


\section{Sequencing}

Double-stranded PCR products were separated in a $2 \%$ Nusieve (FMC

Corporation, Rockland, MD) agarose gel in TAE buffer, and stained with ethidium bromide. DNA bands were excised from the gel matrix, and purified using a Geneclean Kit from BIO 101 (Appendix A). The sequence protocol used in this research was a modification based on the Sanger method with technical specifications according to Sambrook et al. (1989) and using a USB Sequenase kit (Appendix B). Double-stranded products were directly sequenced in 6\% polyacrylamide gels at $55 \mathrm{~W}$ for 3-3.5 hours in a Stratagene BaseAce sequencing apparatus.

Analyses

Resultant sequences were read into a computer with a gel reader pen (IBI) and checked at a later date by eye. Sequence data were analyzed phylogenetically with the Phylogenetic Analysis Using Parsimony (PAUP) program for Maclntosh (Swofford 1993), and with the unweighted pair group method with arithmetic averages (UPGMA) program (Sneath and Sokal 1973). I chose the European river otter as the outgroup because it is one of the closest related species to the sea otter in the subfamily Lutrinae.

To quantify the polymorphisms found in the control region, I calculated haplotype frequencies for each geographic locality, and determined significance using a chi square contingency test. The average nucleotide diversity $(p)$ within each subpopulation was calculated using the formula $p=\sum f_{i} f_{j} p_{i j}$ where $f_{i}$ and $f_{j}$ are the frequencies of the ith and $j$ th haplotypes in the population, and $p_{i j}$ is the 
sequence divergence between these haplotypes (Nei 1987; Avise 1994). Mean nucleotide sequence divergence within and between Alaska and California populations of sea otters was determined using the formula $p=z_{d} / z_{t}$ (where $z_{d}$ is the number of nucleotides which differ between two sequences, and $z_{t}$ is the total number of nucleotides compared, Table 2; Nei 1987, Avise 1994).

Adequacy of sample size was assessed by plotting the number of new haplotypes found as a function of sample size (modified from Bros and Cowell 1987) and by calculating the binomial probability that a rare haplotype of less than $1 \%$ and $5 \%$ frequency would not be detected. 


\section{RESULTS}

A total of 317 basepairs were sequenced from 70 amplified DNA samples. Six samples were destroyed due to human error, and four did not amplify. A working sample size of 70 was as follows: Attu Island $(n=6)$, Amchitka Island $(n=6)$, Adak Island $(n=7)$, Prince William Sound $(n=25)$, and California $(n=26)$. Approximately 18 to 20 samples were necessary to adequately assess the number of haplotypes in sea otters off Alaska, and approximately 8 to 10 samples were required off California (Figs. 4A and B).

Of the 70 samples, seven California individuals were identified using SSCP-PCR (sample autoradiograph, Fig. 3). This technique was effectively used as a screening process for 24 unknown (i.e. of unidentified haplotype) Alaska samples. Using this procedure, no new haplotypes were found in the remaining unknown Alaska samples (i.e. all unknowns possessed one of the known haplotypes identified by previous sequencing). To be cost efficient, only the heavy strand of the remaining 24 samples; therefore, was sequenced to identify the haplotypes of these individuals.

Four haplotypes, derived from three polymorphic locations in the $317 \mathrm{bp}$ segment of the control region were identified. These three polymorphisms, all transitions, occurred within an $18 \mathrm{bp}$ fragment at the $5^{\prime}$ end of the control region (Fig 5). The haplotypes were defined as follows: AK1-adenine at position 12 and thymine at position 29, AK2-guanine at position 12 and cytosine at position 29, CA1-cytosine at position 13, and thymine at position 29, CA2-thymine at both positions 13 and 29 (Fig. 5). Of the four haplotypes, two were unique to the Alaska subpopulations (AK1 and AK2) and two unique to the California 
population; (CA1 and CA2) with no overlap between populations (Table 1). The AK1 and AK2 haplotypes occurred in each subpopulation except Attu Island, where only the AK1 haplotype was found.

Overall, control region sequences were similar (Fig. 6). In this example of Alaska sea otters, all animals except AD91114 are haplotype AK2. Sea otters sharing this haplotype were segregated by distances of approximately 200 to $1000 \mathrm{~km}$.

Within Alaska, the AK2 haplotype was more than twice as abundant as AK1, except at Adak Island where AK1 was more common. The AK1 genotype frequency was 0.182 , whereas the AK2 genotype frequency was 0.818 . In the California population approximately twice as many sea otters had the CA2 haplotype compared with the CA1 haplotype. Genotype frequency was 0.346 for $\mathrm{CA} 1$ and 0.654 for CA2. There was a significant difference in haplotype frequencies between the Alaska and California populations $\left(x^{2}=70.5, p<0.01\right)$

Mean sequence divergence between the Alaska and California populations of sea otters was 0.3 to $0.6 \%$, and one or two absolute differences were found between genotype pairs (Tables 2 and 3). Sequence divergence values within populations were calculated as $0.3 \%$ based on one difference in the California population and as $0.6 \%$ based on two differences in the Alaska sea otters. Nucleotide diversity within the Alaska $(p=0.09 \%)$ and California $(p=0.07 \%)$ populations of sea otters were comparable. Nucleotide diversity was $0.12 \%$ for California and Alaska samples combined.

Both PAUP and UPGMA phylogenetic analyses of the data yielded no viable trees. A geographic distribution of haplotypes was not upheld in any case. The programs weighted data similarly; hence, trees and branches were 
interchangeable due to a paucity of variable sites. However, I was able to create a network of the shortest possible distance among haplotypes. This network illustrates the relationship of haplotypes based on changes in mtDNA sequences (Fig. 7). 


\section{DISCUSSION}

A smaller sample size was necessary to adequately characterize genetic structure of the California population of sea otters than the Alaska population. This probably is because both California haplotypes were relatively frequent in that population, whereas in the Alaska population, one haplotype, (AK1), occurred less frequently than the other. Sample size must be large enough to ensure that all rare haplotypes are found. Sample sizes in this study appeared sufficient. The probability of not detecting a rare haplotype of $5 \%$ frequency or less was calculated as $26 \%$ for the California population, and as $10 \%$ for the Alaska population. There was a $77 \%$ chance that a haplotype of $1 \%$ frequency or less was missed in the California population, and a $31 \%$ chance that such a haplotype was missed in the Alaska population. Hence it is possible that rare alleles, especially in the California population, are not represented in my samples. Perhaps these rare or localized haplotypes may not be represented due to limited geographic sampling throughout the range of the sea otter.

Three polymorphic sites were found within a $17 \mathrm{bp}$ span of the control portion of the mtDNA genome. This region may be more susceptible to point mutations and nucleotide rearrangements than the other $317 \mathrm{bp}$ that were sequenced. This is indicated in haplotype structure, where these three positions produced four haplotypes.

In each sea otter population, one haplotype may be the ancestral form of the other. This phenomenon may be evidenced in the shortest possible network among haplotypes (Fig. 7). For example, in the California population of sea otters, the CA1 haplotype may be derived from the CA2 haplotype, as evidenced 
by the single transitional change. In addition, this network indicates that both the $A K 1$ and $A K 2$ haplotypes branch from the CA2 haplotype. This pattern may reflect some phylogenetic structure of these populations, where the sea otters off Alaska group together and the sea otters off California group together.

Some mixing is probably occurring among Alaska locations because mtDNA sequences of sea otters separated by distances of $200 \mathrm{~km}$ or greater were identical. Some evidence for this is the recent recolonization of Attu Island. Animals probably migrated to this island from either the Commander Islands to the west or from islands further east in the Aleutian archipelago. Genetic mixing of subpopulations probably occurs in steps, from one sea otter colony to the next. It is improbable that sea otters are migrating more than $1000 \mathrm{~km}$ in a single journey. Male sea otters off Alaska typically move distances of $100 \mathrm{~km}$, whereas females move lesser distances (Garshelis et al. 1984). Because of the matrilineal mode of inheritance of mtDNA, my results are indicative only of genetic variability within female sea otters. The distances of movements of female sea otters, however, are probably underrepresented and have not been fully documented (Riedman and Estes 1990).

There was a significant correlation between geography and haplotype distribution for each sea otter population. Haplotypes CA1 and CA2 were found only off California, and the AK1 and AK2 haplotypes were found only off Alaska. This genetic subdivision indicated that the Alaska and California populations of sea otters were genetically distinct. Among Alaska subpopulations of sea otters, Adak Island appeared to possess different haplotype frequencies compared with the other sampling locations (because the AK1 haplotype is more common than 
the AK2 haplotype). No definite conclusions can be made, however, until more subpopulations are examined.

The slightly greater nucleotide divergence and nucleotide diversity values found in the Alaska sea otter population indicated a greater degree of differentiation within this population than within the California population. Nucleotide divergence and nucleotide diversity values for both sea otter populations also are greater than those derived from allozyme data by Rotterman (1992) and are comparable to values of Sanchez (1992). Rotterman (1992) calculated a genetic distance of 0.001 to 0.006 , and found relative differentiation among all populations was great at two loci. My results indicated greater levels of genetic variation mainly due to the greater variability detectable at this loci. Allozymes have a lower mutation rate and lower resolution of variability than the mitochondrial genome (Avise 1994). Sanchez (1992) calculated a $0.512 \%$ mean nucleotide sequence divergence between the California and Prince William Sound populations. This mean nucleotide sequence divergence value lies within the range I found (0.3 to $0.6 \%$ ) between the Alaska and California populations of sea otters. The nature and location of the polymorphisms constituting the divergence values of Sanchez (1992) are unknown.

The nucleotide divergence values obtained for sea otters are low when compared with values found in other marine mammal species (Table 3). Average values of nucleotide divergence for the California sea lion, common dolphin, northern and southern elephant seal, killer whale, spotted and spinner dolphins are an order of magnitude greater than those found in sea otters (Hoelzel and Dover 1991; Dizon et al. 1991, Hoelzel et al. 1993, Rosel et al. 1994; Maldonado et al. 1995). Even the northern elephant seal population, 
which has endured severe reduction in population size, has a greater nucleotide divergence value than the sea otter. However, low nucleotide divergences were found between humpback whale subpopulations off Alaska, central California, Hawaii, and the Gulf of Maine. The larger number of haplotypes found in these populations, however, indicated a more variable gene pool than was found in the sea otter (Baker et al. 1990).

Several plausible explanations exist for the dearth of genetic variation found within the California and Alaska populations of sea otters. The population bottleneck may have drastically reduced the levels of genetic variation in the founding gene pool. However, a typical bottleneck encompasses much more than a reduction in population numbers. Low genetic diversity, disease, recovery time, inbreeding depression, longevity, size and number of bottlenecks all must be considered tc fully characterize the scope and magnitude of a bottleneck effect (Lewontin 1974; Lande 1980; Amos and Hoelzel 1992). In addition, it is possible that not enough time has passed for mutation effects to occur.

Increased population growth rate, less extreme bottleneck, and a relatively large founding population may explain the slightly greater levels of nucleotide divergence found in the Alaska population of sea otters. I expected much greater genetic variation in this population (compared with California) because of its greater population size. In this instance, a less pronounced bottleneck appears to be correlated with a more variable post-bottleneck gene pool. A similar phenomenon was found to a greater extent in the southern elephant seal population (Hoelzel et al. 1993). This population, along with the northern elephant seal population, endured a reduction in numbers. However, the effect was more pronounced in the northern elephant seal, which was 
reduced to lower population levels than the southern elephant seal. Genetic variation was significantly greater (23 haplotypes) in the southern elephant seal population than in the northern elephant seal population ( 2 haplotypes; Hoelzel et al. 1993).

A second possible reason for low genetic variability in these sea otter populations may be that low variation existed before the bottleneck. In effect, there was a bottleneck on population size but not on genetic resources. This idea is supported by Ralls et al. (1983) proposal that the present California population of sea otters has retained 77 percent of its genetic diversity. Low diversity at present does not necessarily equate with high diversity in the past.

If genetic variation of present sea otter populations is equal to that of historical populations, why is the California population recovering so slowly? As discussed earlier, other factors besides genetics may be affecting population growth rate, such as pollution, decreased prey availability, decreased habitat availability, or undocumented influences. Estimates of the original population size also may be incorrect. For example, perhaps the historical sea otter population off California was only 2,000 animals. If this were true, then the present population would be regarded instead as having fully recovered from bottleneck effects. The remaining haplotypes in the California population of sea otters also may not be well-suited for that environment, whereas the genetic structure of the Alaska population may allow for greater fitness in that environment.

A third explanation for the low genetic variation in the sea otter is an evolutionary constraint on the mitochondrial genome of this animal. Low genetic variation occurs in all portions of the mtDNA genome for the mustelids (Koepfli 
pers. comm.). In addition, allozyme studies of various mustelid species including populations of the black-footed ferret (Mustela nigripes), stoat ( $M$. erminea), polecat (M. putorius), weasel (M. nivalis), and European badger (Meles meles) have revealed strict monomorphism across $21 \mathrm{loci}$, indicating a uniformity of genetic structure in this family (O'Brien et al. 1989). This anomaly in control region variation may be a problem of scale. The universal molecular mtDNA clock, set at $2 \%$ sequence divergence/myr, is typically used to calibrate variation in higher organisms. Although this tenet is widely accepted, several departures have been documented. For example, unusually low genetic variation occurs in several species of turtles in the Order Testudines. A molecular clock for this order was calibrated at approximately $0.25 \%$ sequence divergence/myr. The long generation time and slow metabolic rate of these animals may be influencing the evolution rate of their DNA sequences (Avise et al. 1992). Other exceptions have been found in the Hawaiian Drosophila (DeSalle and Templeton 1988 ) and in homeothermic vs. heterothermic vertebrates (Kocher et al. 1989; Thomas and Beckenback 1989). It is possible that the 0.3 to $0.6 \%$ sequence divergence found for sea otters is large in terms of mustelid variation levels. These high levels of variation may be due to ineffective functional constraints or mechanisms of mtDNA repair. As such evidence increases, it becomes clear that universal clock concept needs to be redefined, and that uniformity in evolution rates across thousands of different taxa cannot be assumed.

Another explanation for low variation observed in the sea otter is that the location examined for genetic variability is incorrect. It is possible that more genetic variation exists in other portions of the mitochondrial or nuclear genome. It is unlikely that more genetic variation exists in the mitochondrial genome 
because values of nucleotide divergence in my study are comparable to those found by Sanchez (1992) who examined the entire mtDNA genome via restriction fragments. Additionally, the control region of the mtDNA D-loop is the fastest evolving genome known. The amount of genetic variation found in this molecule is more susceptible to overrepresentation due to enhanced mutation rate. It is possible that the nuclear genome may be more informative than the mitochondrial, despite its slower mutation rate (Moritz 1994).

Lastly, low genetic variation may be an artifact of sampling design. For example, if sea otters were sampled from one group in each location, it is possible that some samples are related. The more closely related a group of animals are, the more similar their genetic structure. Even if family groups were sampled at each location, however, you would expect to see genetic divergence among groups. It seems unlikely then that sampling is responsible for low genetic variation levels because samples were taken during different years and from different locations.

If low genetic variation is truly representative of the sea otter genetic structure, then the issue of population status and viability must be addressed. $A$ decreased genetic diversity in a population does not necessarily lead to a decrease in fitness. Many successful species have low heterozygosity levels (Avise, 1994; Moritz 1994). The northern elephant seal population for example, possesses minimal variation and yet is burgeoning, with a current estimated population size of greater than 100,000 animals (Hoelzel et al. 1993). The Alaska population of sea otters also has regained its probable historic population abundance despite low genetic variation levels. Rapid recovery of numbers of individuals in these populations may be attributed to large effective population 
sizes. If the effective population size of a group of animals is a large enough fraction of the overall population size, then inbreeding depression will not have deleterious effects on the individuals (Price and Waser 1979; Ralis et al 1988, Laiker and Ryman 1991; Avise 1994).

Decreased genetic variation may not necessarily be an indicator of how well a species is doing at present, but rather of how well it might do in the future if environmental conditions changed. Heterozygosity is essential for a population's continued probability of survival (Avise 1994). For example, the cheetah, which possesses minimal genetic variation, was nearly decimated by a virus that killed two-thirds of the captive population in a three-year period (O'Brien and Everman 1988). A similar phenomenon could potentially occur in the small California population of sea otters if a fatal disease pervaded this group of animals.

Based on my results and available information, I accept my hypotheses that there are significant, albeit low, levels of genetic variation and genetic divergence within and between the Alaska and California populations of sea otters. The first hypothesis is accepted due to low levels of genetic variation found in mustelids. On this scale, nucleotide divergences of 0.3 to $0.6 \%$ may be large. These nucleotide divergence values and haplotype number are much smaller than the significance levels determined from other studies on marine mammals. However, it is difficult if not impossible to arbitrarily assign significance levels in order to determine the taxonomic status of animal groups (Avise 1994). I believe it is better to be conservative when determining genetic significance because these values ultimately may be used in subspecies 
designation (especially as the California population of sea otters is designated a threatened population).

The second hypothesis of genetic divergence is accepted because of the lack of overlapping haplotypes between the two populations. Each sea otter population can be differentiated based on its unique haplotypes. Ecological differences between the two populations may reflect this genetic divergence or may be due to environmental influences. For example, the larger body size exhibited by sea otters off Alaska could be attributed to Bergmann's rule, that for a given species, individuals living in colder climates will be larger-bodied than individuals living in warmer regions (Gittleman 1985). Carrying capacity also may be responsible for some ecological differences between these populations. For example, many sea otter populations in the central Aleutian Islands are at carrying capacity; therefore, they feed on more diverse prey items such as fish and sand dollars. A positive correlation between increased body size and prey size and diversity also may influence this feeding behavior (Gittleman 1985).

Based on these results, I believe that the California and Alaska populations of sea otters should be considered separate evolutionary significant units (e.s.u., Ryder,1986). I define e.s.u. as a reproductively isolated, genetically distinct group of individuals. This division upholds the designation advocated by Roest (1971), Davis and Lidicker (1975), and Wilson et al. (1991), for which the Alaska population is one subspecies and the California population is another. However, I do not believe that these groups should be managed as separate subspecies, but rather as separate populations. I believe managers should not uphold the subspecies designations because these populations constituted one 
population originally and in my opinion, three basepair differences are not enough to merit subspecies identification.

My recommendation for management and conservation is to work towards increasing the recovery rate of the California population of sea otters, thereby also increasing range. The reasons why the California population of sea otters is not recovering as quickly as the Alaska population should be determined, and then factors in the environment that are hindering recovery should be eliminated. The main reason for stimulating the recovery rate of the California population of sea otters is that with its small range and low genetic variability, it is vulnerable to a large scale oil spill or infectious disease, either of which could potentially decimate the entire population. If this were to occur, it would be unlikely that sea otters would continue to exist along the California coast, even if translocation of sea otters from Alaska was attempted. The majority of sea otter translocations to uninhabited areas have not been successful (Riedman and Estes, 1990). In this sense, the sea otter population off California merits the threatened population designation. I believe that this designation should remain until the range of this animal expands far enough such that it is less vulnerable to environmental fluctuations. It is hoped that the large range of the sea otter population off California would afford some protection against decimation, since it is unlikely that the current levels of genetic variation would help survivorship. I believe that more effort should be placed on recovery and range expansion rather than increasing genetic variation of this population, because low levels of genetic variation also exist in the Alaska population of sea otters, which is doing fine. (Unless of course, future information from other molecular markers proves otherwise). 
One means of increasing genetic diversity within the California population of sea otters however, might be to crossbreed these animals with individuals from the thriving Alaska population. If crossbreeding is viable, then I suggest augmenting the California population of sea otters with individuals from the Alaska population. Unlike prior translocation attempts, this strategy would move animals to regions where other sea otters already exist. It is hoped that the genetic variability of sea otters off California would eventually increase, as would fitness. Perhaps as fitness levels increased, the range of these animals off California also would increase. Reproductive compatibility would cause sea otters from Alaska and California to comprise one e.s.u. Progeny could be tracked easily and identified genetically by SSCP-PCR and/or double-stranded sequencing. The political issue of mixing two subpopulations can be eliminated if one remembers that the sea otter was one population originally, and probably still would be if it were not for human interference.

The present management agenda for the California population of sea otter has been limited to annual censuses, translocation attempts, and rehabilitation. With the exception of censuses, these strategies are too narrowly focused on limited numbers of animals. I suggest instead that more effort go towards applied research. For example it would be helpful and perhaps critical to know how toxins, disease, parasites, poor water quality, and boat traffic affect these animals. It would be beneficial also if comparative studies were conducted on animals from Alaska and California locations. These studies would allow for direct comparisons of animals that are thriving (off Alaska) with animals that are not (off California). 
Before a comprehensive management plan can be formulated for the sea otter, more genetic studies should be conducted. Data obtained from several different genetic techniques are desired when developing a species management plan (Cronin 1993). Each technique provides unique and valuable information on the genetic structure of a population. One new informative molecular marker is the microsatellite.

Microsatellites are nuclear markers comprised of arrays of repeated sequences two to six nucleotides in length, which may be highly polymorphic, having as many as a dozen or more alleles at a single locus (Tautz 1989; Litt and Luty 1989; Rassman et al. 1991; Moore et al. 1991). Microsatellites have a high mutation rate, and are excellent for detecting variability that cannot be found by other molecular markers (Hughes and Queller 1993). Microsatellites ultimately may provide information on the allele frequencies (at given loci) in a population. These frequencies can be used in population and kinship studies to predict Hardy-Weinburg frequencies, to identify degrees of relatedness among individuals, or to determine social and reproductive behavior of individuals.

Preliminary analysis of sea otter microsatellites was performed in conjunction with mtDNA sequencing work. Three microsatellites were successfully isolated, one of which was polymorphic. This microsatellite, identified as locus Llu3/252, revealed a $30 \%$ heterozygosity level in a sample of 20 sea otters from Alaska and $100 \%$ homozygosity in an equal sample size of sea otters from California (Fig. 8). This is a promising result that merits further investigation. This result, albeit preliminary, may indicate that the slow recovery in the California population of sea otters is due to homozygote inferiority. The Alaska population may be better suited to the environment due to heterosis and 
because a mix of heterozygotes and homozygotes enhances the robustness of the gene pool. These results are only preliminary, and more microsatellites must be screened before any real conclusions can be made.

More studies need to be conducted before a complete understanding of sea otter population genetics can be attained. An estimate of pre-bottleneck population diversity should be determined. This is possible now with ancient DNA techniques that allow amplification of DNA from preserved skins, hair samples, and bone. Historic values of genetic diversity within both the Alaska and California populations of sea otters would allow for a direct comparison of variability before and after population bottleneck. Assessment of the genetic variation in the Russian population of sea otters would help to provide genetic information for all extant sea otter populations. Novel techniques such as microsatellites, or perhaps one that has yet to be developed, may be the key to fully quantifying genetic variation or lack thereof, in the sea otter. 


\section{LITERATURE CITED}

Allendorf, F.W. 1986. Genetic drift and the loss of alleles versus heterozygosity. Zoo. Biol. 5:184-190.

Ames, J.A., R.A. Hardy, F.E. Wendell and J.J. Geibel. 1983. Sea otter mortality in California. Mar. Res. Branch, California Department of Fish and Game. Monterey, California. 124 pp.

Amos, B. and A.R. Hoelzel. 1992. Applications of molecular genetic techniques to the conservation of small populations. Biol. Conser. 61:133-144.

Avise, J.C. 1992. Molecular population structure and the biogeographic history of a regional fauna: a case history with lessons for conservation biology. Oikos. 63:62-76.

Avise, J.C., B.W. Bowen, T. Lamb, A.B. Meylan and E. Bermingham. 1992. Mitochondrial DNA evolution at a turtle's pace: evidence for low genetic variability and reduced microevolutionary rate in the Testudines. Mol. Biol. Evol. 9:457-473.

Avise, J.C. 1994. Molecular markers, natural history and evolution. Chapman and Hall. New York, New York. 511 pp.

Bacon, C.E., J.A. Estes, W.M. Jarman, R.J. Norstrom, and M. Simon. 1993. Organic contaminant levels in sea otters (Enhydra lutris) from California, Southeast Alaska, and the Aleutian Islands. Abstract from the Fourth Annual Monterey Bay Research Symposium. Feb. 5, 1993. Monterey, California.

Baker, C.S., S.R. Palumbi, R.H. Lambertsen, M.T. Weinrich, J. Calambokidis, and S.J. O'Brien. 1990. Influence of seasonal migration on geographic distribution of mitochondrial DNA haplotypes in humpback whales. Nature. 344:238-240.

Barabash-Nikiforov, I.I. 1962. The sea otter. Israel Program for Scientific Translations, Ltd. Jerusalem. $184 \mathrm{pp}$.

Boolootian, R.A. 1961. Observations of the California sea otter. J. Mammal. 42:271-273. 
Bros, W.E. and B.C. Cowell. 1987. A technique for optimizing sample size (replication). J. Exp. Mar. Biol. Ecol. 114:63-71.

Cronin, M.E. 1993. Mitochondrial DNA in wildlife taxonomy and conservation biology: cautionary notes. Wildl. Soc. Bull. 21:339-348.

Davis, J.D. and W.Z. Lidicker, Jr. 1975. The taxonomic status of the southern sea otter. Proc. Calif. Acad. Sci., 4th ser. 40:429-437.

DeSalle, R. and A.R. Templeton. 1988. Founder effects and the rate of mitochondrial DNA evolution in Hawaiian Drosophila. Evol. 42:10761084.

Dizon, A.E., S.O. Southern and W.F. Perrin. 1991. Molecular analysis of mtDNA types in exploited populations of spinner dolphins (Stenella longirostris). Pp. 261-284 in: Hoelzel, A.R. (ed) Genetic ecology of whales and dolphins. International Whaling Commission. Cambridge, Massachusetts.

Ebert, E.E. 1968. A food habits study of the southern sea otter, Enhydra lutris nereis. Calif. Fish and Game. 54:33-42.

Estes, J.A. 1980. Enhydra lutris. Mamm. Species. 133:1-8.

Estes, J.A., R.J. Jameson and A.M. Johnson. 1981. Food selection and some foraging tactics of sea otters. Pp. 606-641 in: Chapman, J.A. and D. Pursley (eds) The Worldwide Furbearer Conference Proceedings. Worldwide Furbearer Conference. Frostburg, Maryland.

Estes, J.A. and F.R. Jameson. 1983. Size and status of the sea otter pup in California. Technical report, U.S. Fish and Wildlife Service. Santa Cruz, California. $24 \mathrm{pp}$.

Fisher, E.M. 1939. Habits of the southern sea otter. J. Mammal. 20:21-36.

Fisher, E.M. 1940. Early life of a sea otter pup. J. Mammal. 2:132-137.

Frankel, O.H and M.E. Soule. 1981. Conservation and evolution. Cambridge University Press. Cambridge, Massachusetts. 478 pp.

Garshelis, D.L. and J.A. Garshelis. 1984. Movements and management of sea otters in Alaska. J. Wildl. Manage. 48:665-678. 
Garshelis, D.L., A.M. Johnson and J.A. Garshelis. 1984. Social organization of sea otters in Prince William Sound, Alaska. Can. J. Zool. 62:2648-2658.

Gittleman, J.L. 1985. Carnivore body size: ecological and taxonomic correlates. Oecologia. 67:540-554.

Hoelzel, A.R. and G.A. Dover. 1991. Molecular genetic ecology. Oxford University Press. Oxford, England. 75 pp.

Hoelzel, A.R. and G.A. Dover. 1991. Genetic differentiation between sympatric killer whale populations. Heredity. 66:191-195.

Hoelzel, A.R., J. Halley, S.J. O'Brien, C. Campagna, T. Arnbom, B. Le Boeuf, K. Ralls and G.A. Dover. 1993. Elephant seal genetic variation and the use of simulation models to investigate historical population bottlenecks. J. Heredity. 84:443-449.

Hughes, C.R. and D.C. Queller. 1993. Detection of highly polymorphic microsatellite loci in a species with little allozyme polymorphism. Mol. Ecology. 2:131-137.

Kenyon, K.W. 1969. The sea otter in the eastern Pacific Ocean. Bureau of Sport Fisheries and Wildlife. Washington, D.C. 352 pp.

Kocher, T.D., W.K. Thomas, A. Meyer, S.V. Edwards, S. Paabo, F.X. Villablanca and A.C. Wilson. 1989. Dynamics of mitochondrial DNA evolution in animals: amplification and sequencing with conserved primers.

Proceedings of the National Academy of Sciences. 86:6196-6200.

Koepfli, K.P. University of California, Los Angeles. Dept. of Biology. 621 Circle Drive South. Los Angeles, California. 90024. (310)-825-5014.

Laiker, L. and N. Ryman. 1991. Inbreeding depression in a captive wolf (Canis lupus) population. Cons. Biol. 5:33-40.

Lande, R. 1980. Genetic variation and phenotypic evolution during allopatric speciation. Amer. Nat. 116:463-479.

Lensink, K.W. 1975. The history and status of sea otters in Alaska. Ph.D. thesis, Purdue University. University Microfilms, Inc. Ann Arbor, Michigan. $188 \mathrm{pp}$. 
Lewontin, R.C. 1974. The genetic basis of evolutionary change. Columbia University Press. New York, New York. 212 pp.

Limbaugh, C. 1961. Observations of the California sea otter. J. Mammal. 42:271-273.

Litt, M. and J.A. Luty. 1989. A hypervariable microsatellite revealed by in vitro amplification of dinucleotide repeat within the cardiac muscle actin gene. Am. J .Hum. Genet. 44:397-401.

Maldonado, J.E., F.O. Davila, B.S. Stewart, E. Geffen and R.K. Wayne. 1995. Intra specific genetic differentiation in California sea lions (Zalophus californianus) from southern California and the Gulf of California. Mar. Mamm. Sci. 11:46-58.

Miller, D.J. 1974. The sea otter Enhydra lutris. Its life history, taxonomic status and some ecological relationships. Marine Resources leaflet \#7. State of California Department of Fish and Game. 133 pp.

Moore, S.S., L.L. Sargeant, T.J. King, J.S. Mattick, M. Georges and D.J.S. Hetzel. 1991. The conservation of dinucleotide microsatellites among mammalian genomes allows the use of heterologous PCR primer pairs in closely related species. Genomics. 10:654-660.

Moritz, C. 1994. Applications of mitochondrial DNA analysis in conservation: a critical review. Mol. Ecology. 3:403-413.

Nei, M. 1987. Molecular evolutionary genetics. Columbia University Press. New York, New York. 492 pp.

O'Brien, S.J. and J.F. Evermann. 1988. Interactive influence of infectious disease and genetic diversity in natural populations. Trends Ecol. Evol. 3:254-259.

O'Brien, S.J., J. S. Martenson, M.A. Eichelberger, E.T. Thorne, and F. Wright. 1989. Genetic variation and molecular systematics of the black-footed ferret. Pp. 21-33 in: U.S. Seal, E.T. Thorne, M.A. Bogan, and S.H. Anderson (eds) Conservation biology and the black-footed ferret. Yale University Press. New Haven, Connecticut.

Orita, M., Y. Suzuki, T. Seriya, and K. Hayashi. 1989. Rapid and sensitive detection of point mutations and DNA polymorphisms using the polymerase chain reaction. Genomics. 5:874-879. 
Ostfeld, R.S. 1982. Foraging strategies and prey switching in the California sea otter. Oecologia. 53:170-178.

Price, M.V. and N.M. Waser. 1979. Pollen dispersal and optimal outcrossing in Delphinium nelsoni. Nature. 277:294-297.

Quattro, J.M. and C. Vrijenhoek. 1989. Fitness differences among remnant populations of endangered sonoran topminnow. Science. 245:976-978.

Ralls, K. and J. Ballou. 1983. Extinctions: lessons from zoos. Pp. 164-184 in: Chambers, S.M., B. MacBryde and L. Thomas (eds) Genetics and conservation: a reference manual for managing wild animal and plant populations. Benjamin/Cummings. Menlo Park, California.

Ralls, K., J. Ballou and R.L. Brownell, Jr. 1983. Genetic diversity in California sea otters: theoretical considerations and management implications. Biol. Conserv. 25:209-232.

Ralls, K., J.D. Ballou and A.R. Templeton. 1988. Estimates of lethal equivalents and the costs of inbreeding in mammals. Conser. Biol. 2:185-193.

Rassmann, K., C. Schlotterer and D. Tautz. 1991. Isolation of simple-sequence loci for use in polymerase chain reaction-based DNA fingerprinting. Electrophoresis. 12:13-118.

Riedman, M.L. 1987. Final environmental impact statement for translocations of southern sea otters. U. S. Fish and Wildlife Service, Vol 2, Technical Support Documents. $47 \mathrm{pp}$.

Riedman, M.L. and J.A. Estes. 1988. A review of the history, distribution and foraging ecology of sea otters. Pp. 4-21 in: VanBlaricom, G.R. and J.A. Estes (eds) The community ecology of sea otters. Springer-Verlag Publishing. New York, New York.

Riedman, M.L.and J.A. Estes. 1990. The sea otter (Enhydra lutris): behavior, ecology, and natural history. U.S. Department of the Interior Fish and Wildlife Service. Biological Report. 90(14). 126 pp.

Roest, A. I. 1976. Systematics and the status of sea otters, Enhydra lutris. Bull. South. Calif. Acad. Sci. 75:267-270. 
Rosel, P.E., A.E. Dizon and J.E. Heyning. 1994. Genetic analysis of sympatric morphotypes of common dolphins (genus Delphinus). Marine Biology. 119:159-167.

Rote, J.W. 1976. Analysis of chlorinated hydrocarbon pollutants in the marine ecosystem. Ph.D. thesis, Stanford University. Menlo Park, California. $100 \mathrm{pp}$.

Rotterman, L.M. 1992. Patterns of genetic variability in sea otters after severe population subdivision and reduction. Ph.D. thesis, University of Minnesota. Minneapolis, Minnesota. $228 \mathrm{pp}$.

Roy, Michael. University of California, Los Angeles. Dept. of Biology. 621 Circle Drive South. Los Angeles, California. 90024. (310)-825-5014.

Ryder, O.A. 1986. Species conservation and systematics: the dilemma of a subspecies. Trends Ecol. Evol. 1:9-10.

Sambrook, J., E. Fritsch and T. Maniatis. 1989. Molecular cloning: a laboratory manual. Cold Spring Harbor Laboratory Press. Cold Spring Harbor, New York. 182 pp.

Sanchez, M.S. 1992. Differentiation and variability of mitochondrial DNA in three sea otter, Enhydra lutris, populations. M.S. thesis, University of California, Santa Cruz. Santa Cruz, California. $101 \mathrm{pp}$.

Sandegren, F.E., E.W. Chu and J.E. Vandevere. 1973. Maternal behavior in the California sea otter. J. Mammal. 54:668-679.

Schneider, K.B. 1972. Reproduction in the female sea otter. Federal Aid in Wildlife Restoration Project W-17-4, project progress report. Alaska Department of Fish and Game. 8 pp.

Schneider, K.B. 1973. Sea otter report. Alaska Department of Fish and Game. Juneau, Alaska. $121 \mathrm{pp}$.

Shaw, S.B. 1971. Chlorinated hydrocarbon pesticides in sea otters and harbor seals. Calif. Fish and Game. 37:290-294.

Siniff, D.B. and K. Ralls. 1988. Reproduction, survival, and tag loss in California sea otters. In: Siniff D.B. and K. Ralls (eds) Population status of California sea otters. Final report to the Minerals Management Service. U.S. Department of the Interior. 14-12-001-3003, pp.13-32. 
Sneath, P.H.A. and R.R. Sokal. 1973. Numerical Taxonomy. W.H. Freeman and Co. San Francisco, California. 225 pp.

Swofford, D.L. 1993. PAUP: Phylogenetic Analysis Using Parsimony (version 3.1.1). Illinois Natural History Society. Champaign, Illinois.

Tautz, D. 1989. Hypervariability of simple sequences as a general source for polymorphic DNA. Nuc. Acids Research. 17:6463-6471.

Thomas, R.H. and A.T. Beckenbach. 1989. Variation in salmonid mitochondrial DNA: evolutionary constraints and mechanisms of substitution. J. Mol. Evol. 29:233-245.

Vandevere, J.E. 1970. Reproduction in the southern sea otter. Pp. 221-227 in: Proceedings of the 7th Annual Conference on Biol Sonar and Diving Mammals. Stanford Research Institute. Menlo Park, California.

Vandevere, J.E. 1972. Behavior of southern sea otter pups. Pp. 21-35 in: Proceedings of the 9th Annual Conference on Biological Sonar and Diving Mammals. Stanford Research Institute. Menlo Park, California.

Wild, P.W. and J.A. Ames. 1974. A report on the sea otter, Enhydra lutris I., in California. Mar. Res. Tech. Report. \#20:1-94.

Wilson, D.E., M.A. Bogan, R.L. Brownell, Jr., A.M. Burdin and M.K. Maminov. 1991. Geographic variation in sea otters, Enhydra lutris. J. Mammal. 72:22-36.

Woolfenden, J. 1985. California sea otter: saved or doomed? The Boxwood Press. Pacific Grove, California. 220 pp. 
Table 1. Frequency of sea otter mtDNA control region sequence haplotypes by geographic locality.

\begin{tabular}{|c|c|c|c|c|c|c|}
\hline \multirow[b]{3}{*}{ HAPLOTYPES } & \multicolumn{5}{|c|}{ GEOGRAPHIC LOCALITY } & \multirow{3}{*}{ TOTAL } \\
\hline & \multicolumn{4}{|c|}{ ALASKA } & \multirow{2}{*}{ CALIF } & \\
\hline & Attu & Amc. & Adak & PWS & & \\
\hline AK1 & & 2 & 5 & 1 & & 8 \\
\hline AK2 & 6 & 4 & 2 & 24 & & 36 \\
\hline CA1 & & & & & 9 & 9 \\
\hline $\mathrm{CA} 2$ & & & & & 17 & 17 \\
\hline TOTAL: & 6 & 6 & 7 & 25 & 26 & $\overline{70}$ \\
\hline
\end{tabular}


Table 2. Mean nucleotide sequence divergence (above diagonal) and absolute distances among haplotypes (below diagonal) for sea otters off California and Alaska.

\begin{tabular}{lcccc}
\hline HAPLOTYPE & AK1 & AK2 & CA1 & CA2 \\
\hline ALASKA 1 & - & 0.006 & 0.006 & 0.003 \\
ALASKA 2 & 2 & - & 0.006 & 0.003 \\
CALIF. 1 & 2 & 2 & - & 0.003 \\
CALIF. 2 & 1 & 1 & 1 & - \\
\hline
\end{tabular}


Table 3. Marine mammal intraspecific and inter-population mtDNA nucleotide sequence divergence values (\%). Number of haplotypes found and sample size (n) are listed for each study. Values for this study shown in boldface type.

\begin{tabular}{|c|c|c|c|c|}
\hline SPECIES & COMPARISON & NUC. DIV. & \# HAP. & $n$ \\
\hline Enhydra lutris & intra-pop'n & $0.3-0.6$ & 2 & 70 \\
\hline (Cheney 1995) & inter-pop'n & $0.3-0.6$ & 4 & 70 \\
\hline $\begin{array}{l}\text { Zalophus californianus } \\
\text { (Maldonado et al. 1995) }\end{array}$ & inter-pop'n & 4.3 & 11 & 40 \\
\hline $\begin{array}{l}\text { Delphinus delphis } \\
\text { (Rosel et al. 1994) }\end{array}$ & intraspecific & $1.09-1.11$ & 45 & 89 \\
\hline $\begin{array}{l}\text { Mirounga angustirostrus } \\
\text { Mirounga leonina } \\
\text { (Hoelzel et al. 1993) }\end{array}$ & $\begin{array}{l}\text { intraspecific } \\
\text { intraspecific }\end{array}$ & $\begin{array}{c}1 \\
2.3\end{array}$ & $\begin{array}{c}2 \\
23\end{array}$ & $\begin{array}{l}67 \\
48\end{array}$ \\
\hline $\begin{array}{l}\text { Orcinus orca } \\
\text { (Hoelzel and Dover 1991) }\end{array}$ & inter-pop'n & $0.0-1.38$ & & 17 \\
\hline $\begin{array}{l}\text { Stenella attenuata } \\
\text { Stenella longirostris } \\
\text { (Dizon et al. 1991) }\end{array}$ & $\begin{array}{l}\text { intraspecific } \\
\text { intraspecifc }\end{array}$ & $\begin{array}{c}1.7 \\
0.3-1.5\end{array}$ & $\begin{array}{c}7 \\
48\end{array}$ & $\begin{array}{c}10 \\
135\end{array}$ \\
\hline $\begin{array}{l}\text { Megaptera novaeangliae } \\
\text { (Baker et al. 1990) }\end{array}$ & inter-pop'n & $0.11-0.28$ & 12 & 84 \\
\hline
\end{tabular}




\section{Figure captions}

Figure 1. Estimated number of sea otters off California from 1914 to 1994. Lines connect censuses of successive years. Circles indicate single counts. Squares represent the mean of spring and fall censuses conducted in 1982-83, 1985-87, and 1989-94. The range between counts is indicated with a vertical line (with the larger value representing the spring count and the smaller representing the fall count).

Figure 2. Locations where blood was obtained from sea otters, and number of samples $(n)$ obtained per site.

Figure 3. Sample autoradiograph of single-stranded conformation polymorphism-PCR sequencing gel. Samples of known California and Alaska haplotypes are on left (samples \#1-4=CA2, samples \#5-8=CA1, samples \#912=AK2, samples \#13-16=AK1). Samples of unknown haplotype are on far right (samples \#17-18=California unknowns, samples \#19-20=Alaska unknowns). Sample \#1 is used as a size marker throughout the gel.

Figure 4. Adequacy of sample size for Alaska and California populations of sea otters as indicated by a plot of number of new haplotypes found versus the number of samples.

Figure 5. Seventy basepair polymorphic region from sea otters off Alaska and California. Template sequence at top and Ireland river otter (Lutra lutrinae) outgroup at the bottom. Dots indicate like sequence to the template. Samples abbreviated as follows: $A M=A m c h i t k a$ Island, $A D=A d a k$ Island, $A T=A t t u$ Island,

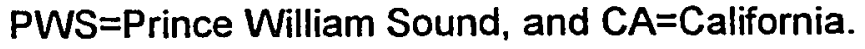

Figure 6. Sample autoradiograph of heavy strand of sea otter mtDNA D-loop sequences. Circles indicate location of polymorphisms. Sample numbers are listed at top of each sequence. Lanes correspond to nucleotides as follows (from left to right) cytosine, thymine, adenine, and guanine. (Read sequence from top of page to bottom).

Figure 7. Network of shortest possible distance among haploiypes. Letters in circles represent three variable sites of sea otter mtDNA sequences. The haplotypes that these variable sites correspond to are listed under the circles. Basepair differences between each haplotype are shown in boldface type.

Figure 8. Autoradiograph of microsatellite locus Llu3/252. Sea otters from California are on the right, sea otters from Alaska are on the left. Sample numbers are listed above microsatellites. M13 size marker is in the middle. Arrow indicates microsatellites. 


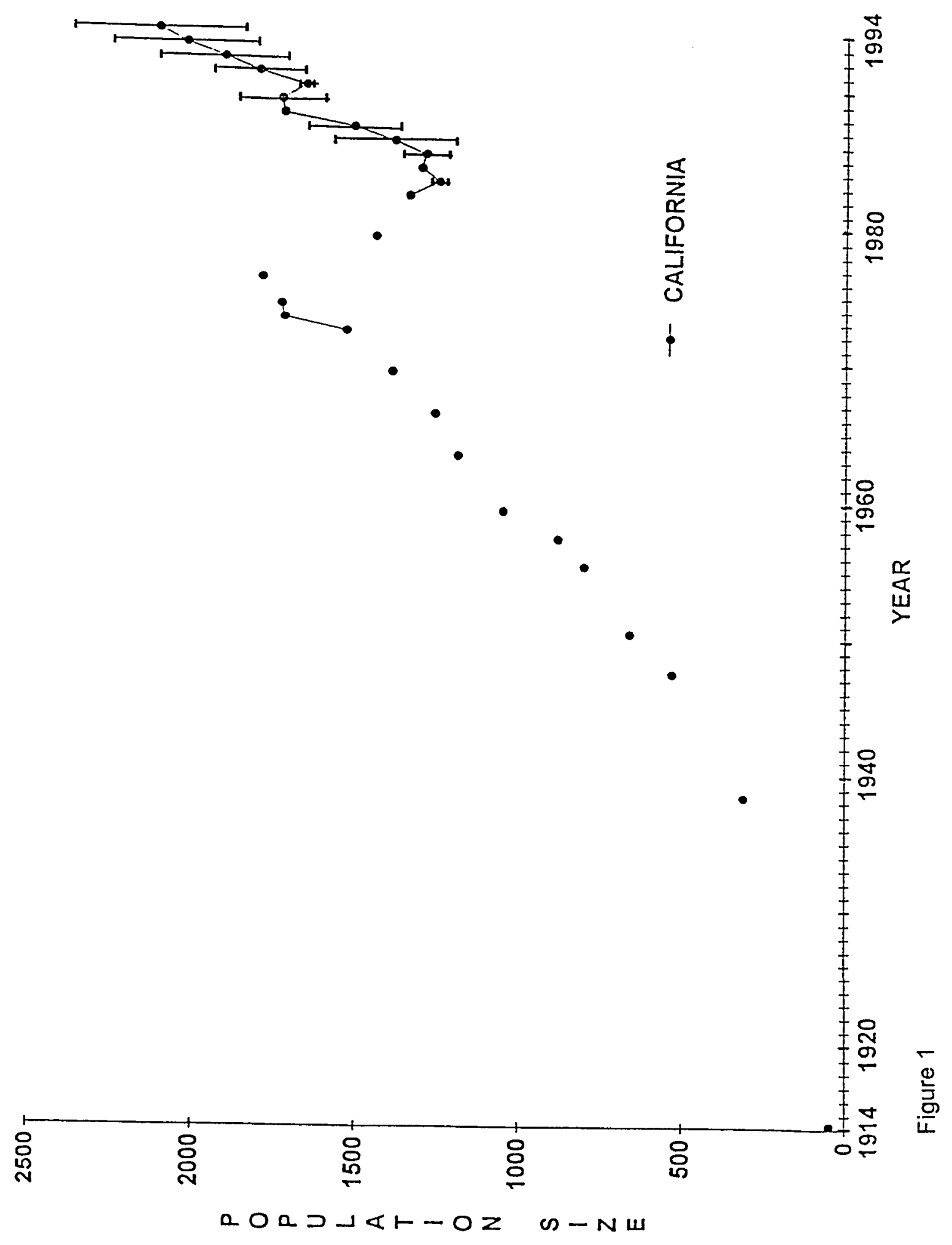




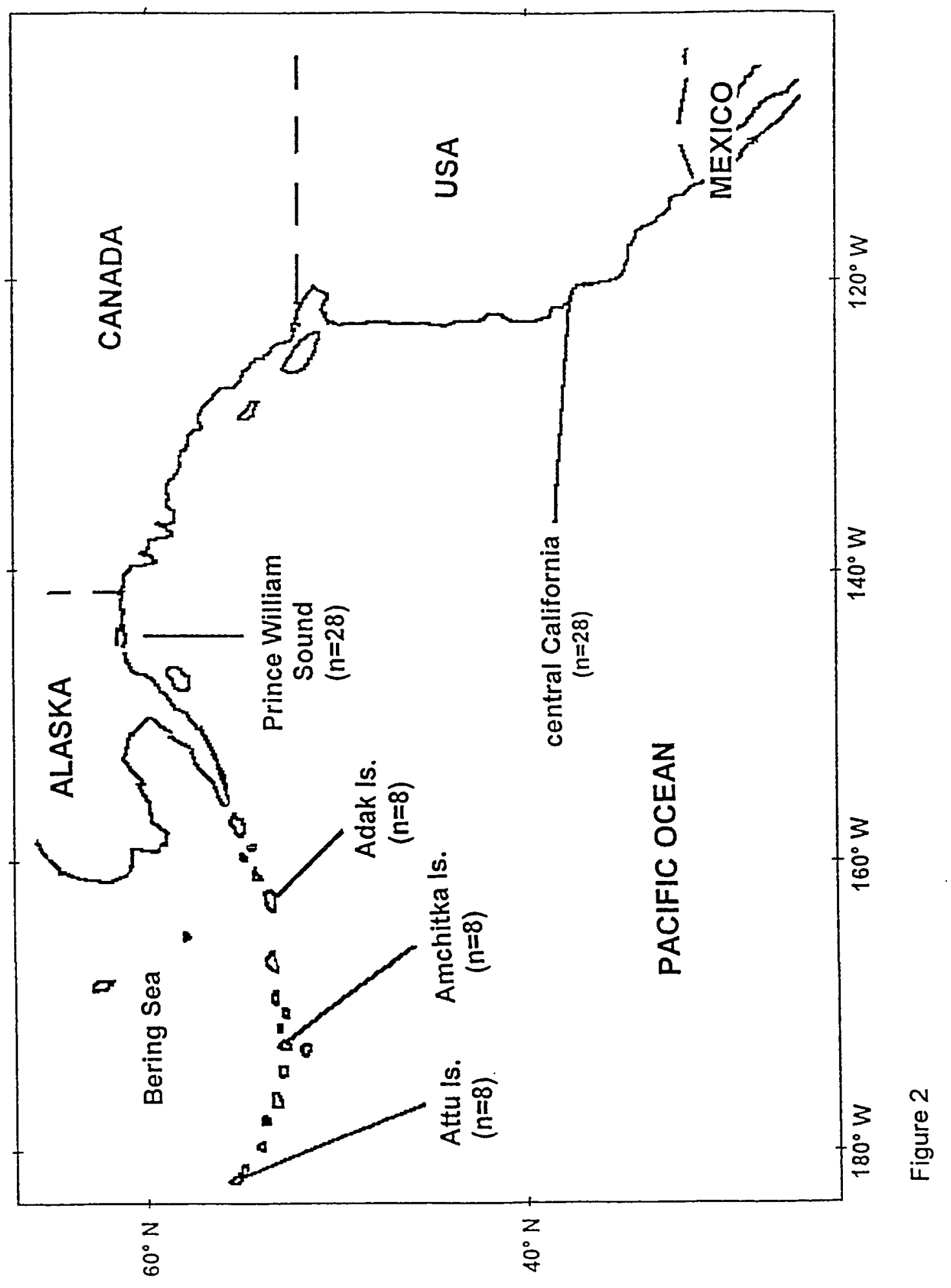




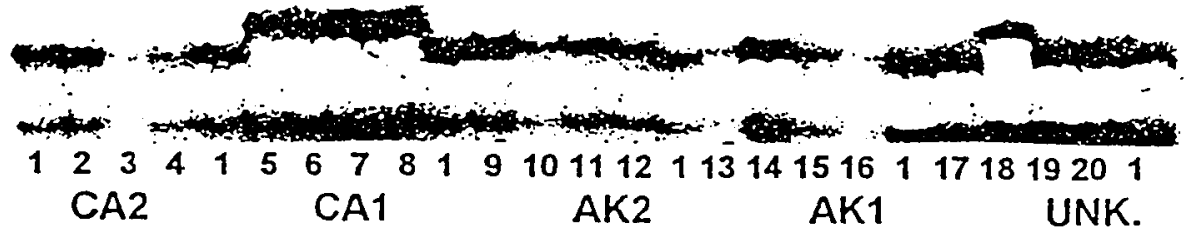

Figure 3 

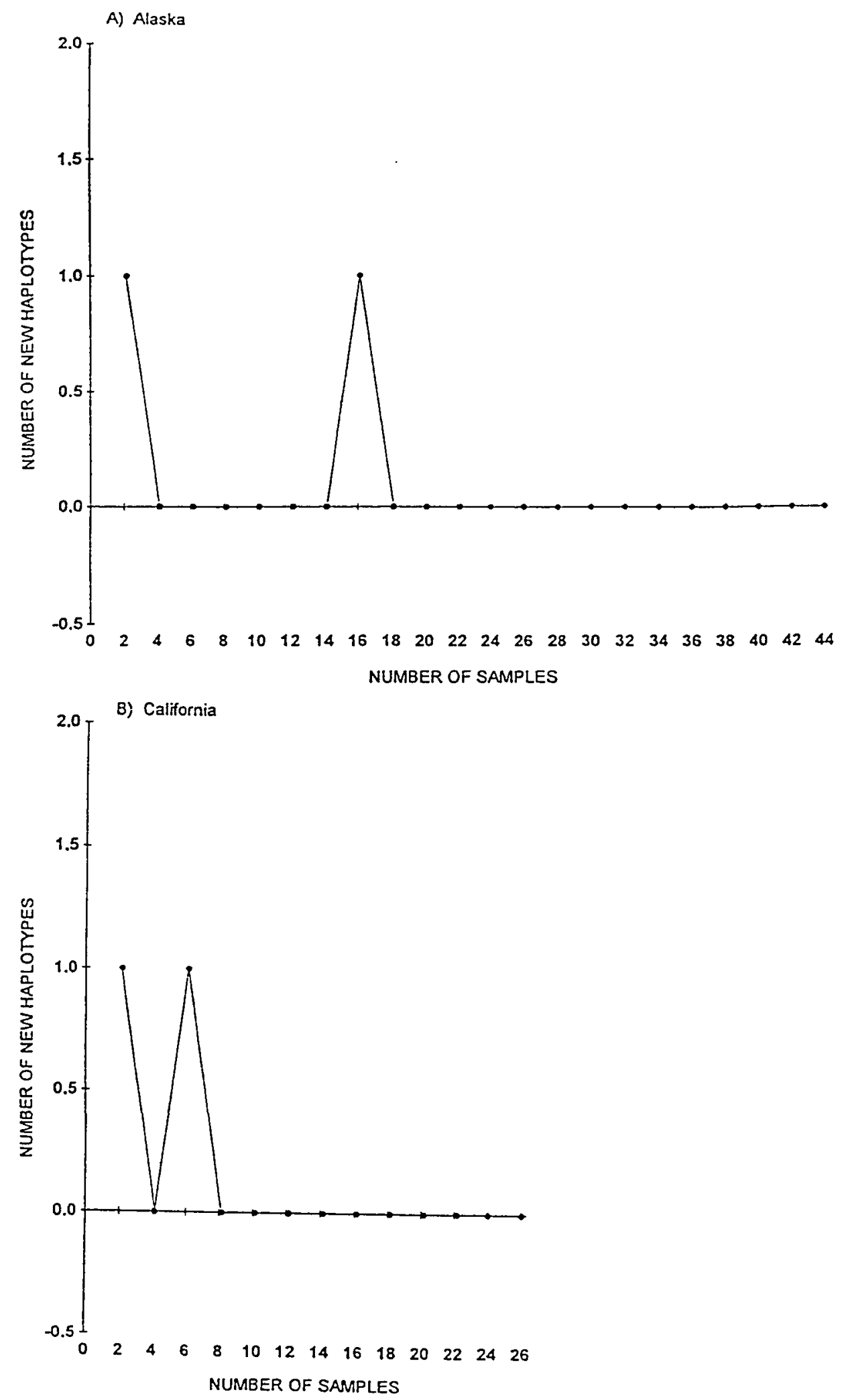

Figure 4 
An92044

AM92047

AM92060

AM9206

A4t92087

AM92083

AD91106

D91106

A091109

AD91110

A091114

A0s1116

AD91118

AT91125

AT91132

AT91133

AT91136

ATr1136

ATS1143

PWS10

PWS102

PWS103

PWS109

PWS10

PWS11

PWS121

PWS16

PWS162

PWS16

PWS16-

PWS166

PWS167

PWST6

PWVICO

PWS4646

PWS4667

PWS4660

PWS4661

PWS91063

PWS91064

PWS91067

PWS91069

PWS91062

PWS91054

CAOO1

CAOO2

CAOOJ

CAOO4

CA175

CA190

CA193

CA194

CA194

CA196

CA197

CA198

CA1SS

CA203

CA204

A206

CA206

CA3879

CAAG60
LLUIRE

Figure 5
TATTATOOTTOOTITACATOTATOCATCTCACCTAOATCACOAGCTTOATCACCATOCCTCOAGA

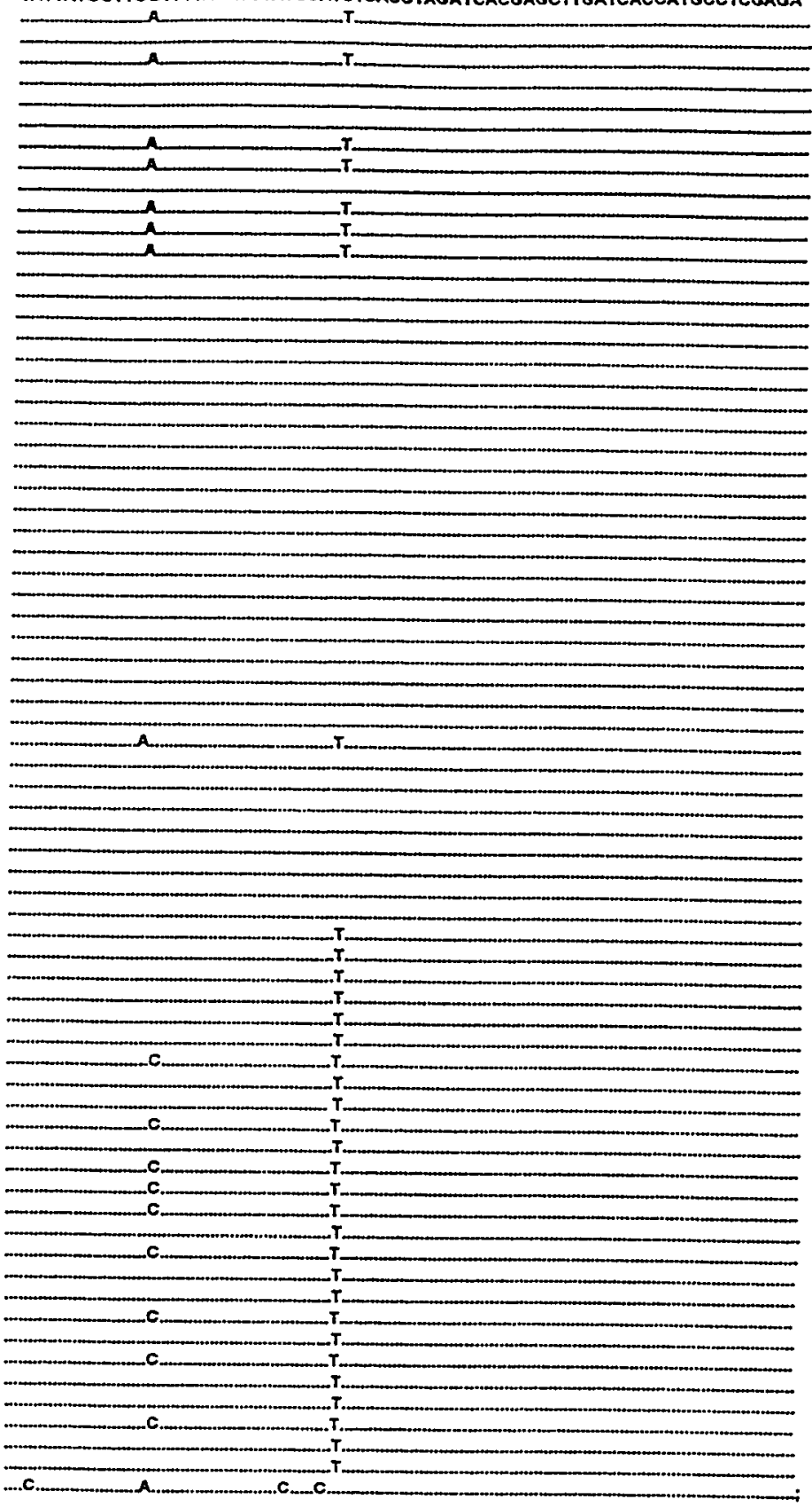




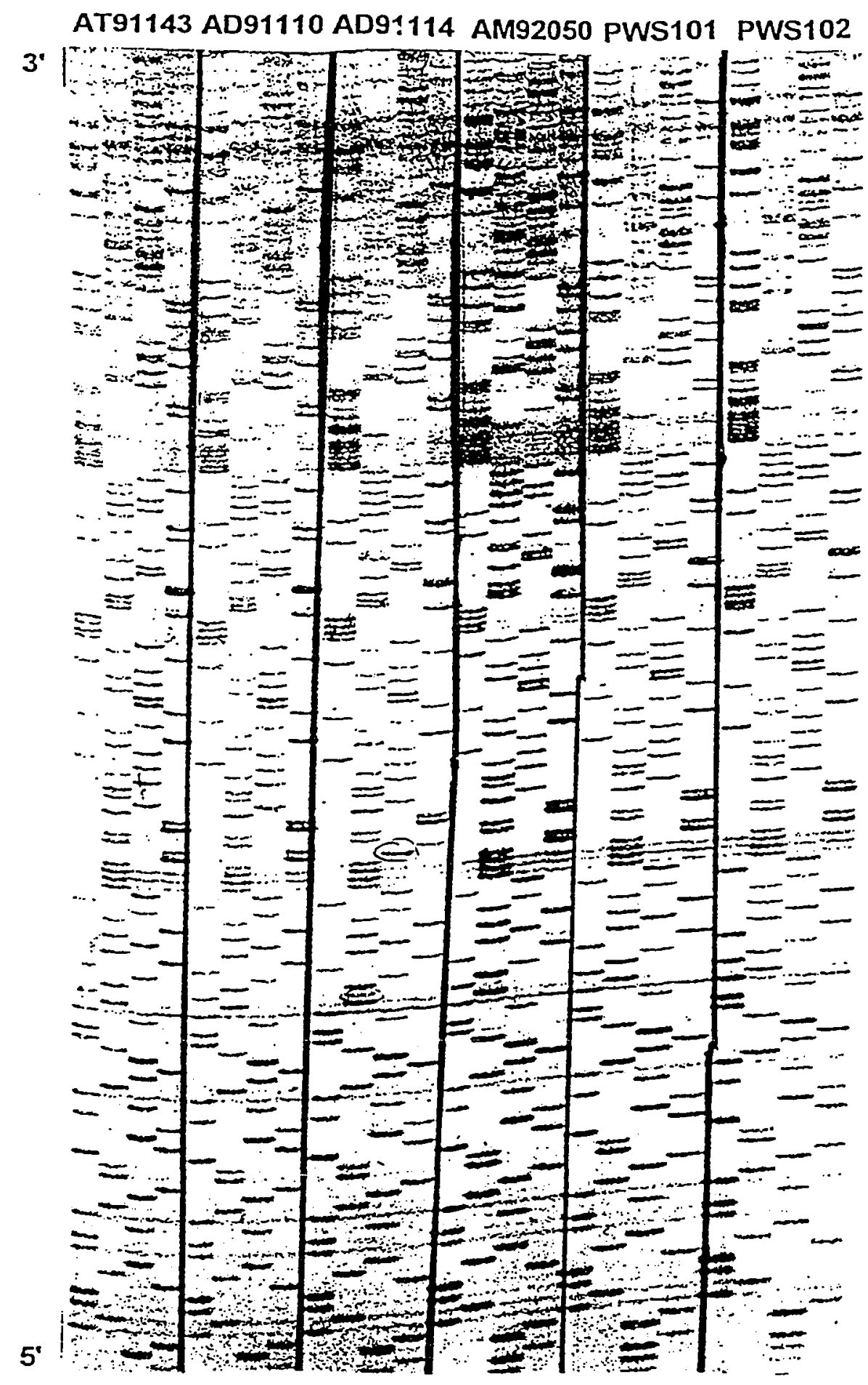

Figure 6 


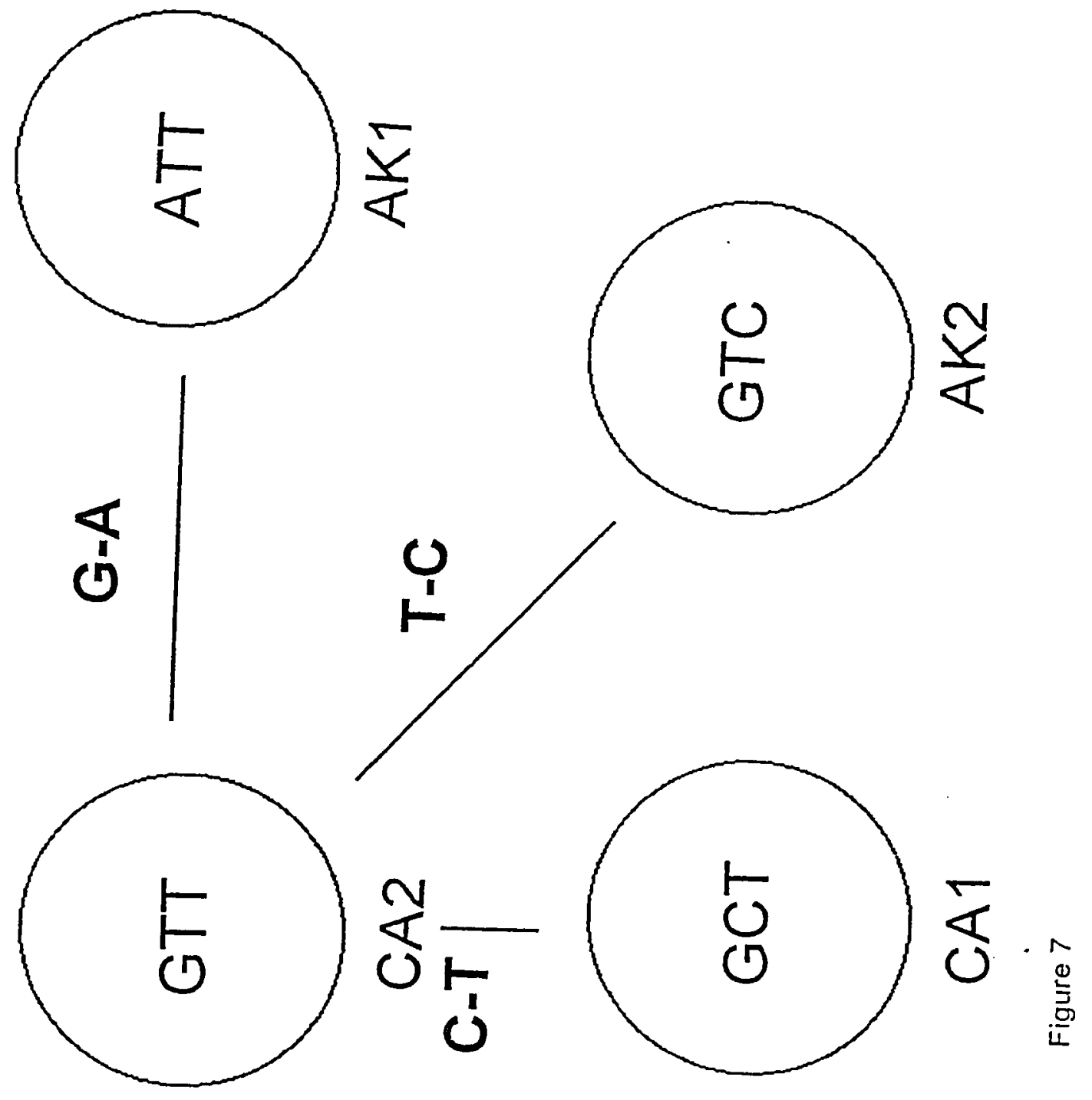




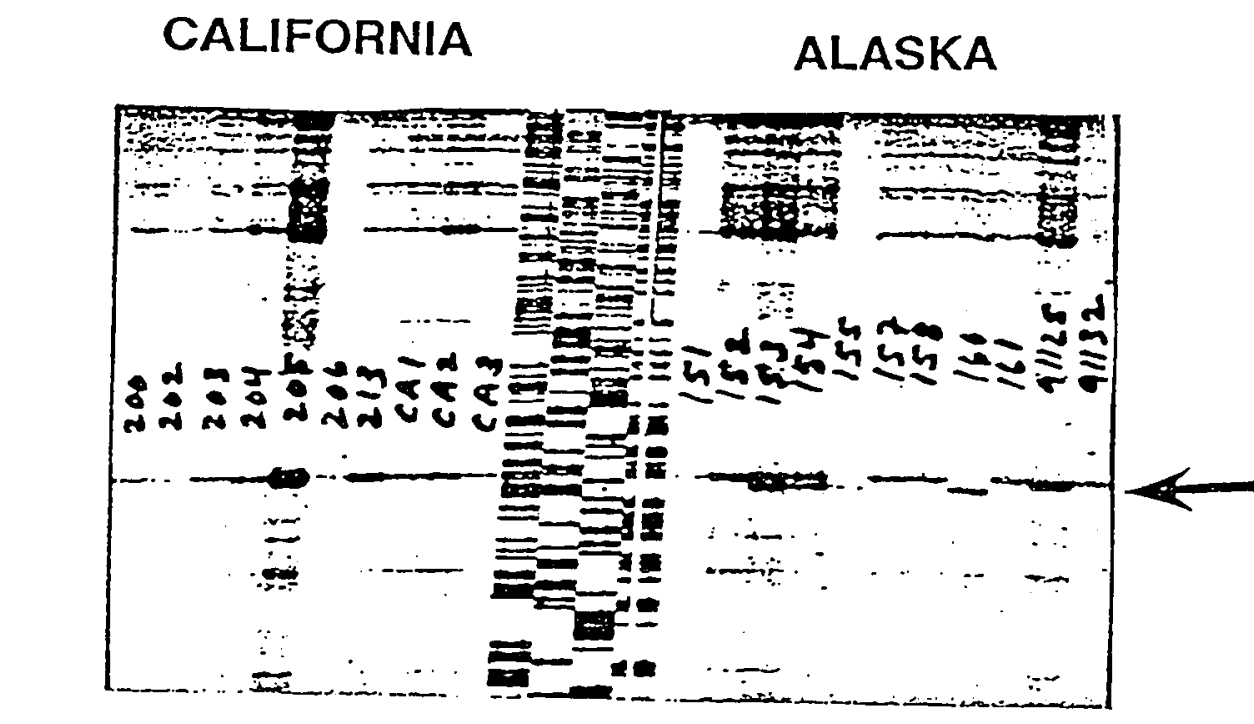

\section{MICROSATELLITE LOCUS LLU3/252}

Figure 8 


\section{APPENDICES}

(A). GENECLEAN PROTOCOL (from Wayne lab protocol).

1. Spin down gel slice in microcentrifuge and estimate volume.

2. Add Nal, three times the volume of the gel slice.

3. Place in $55^{\circ} \mathrm{C}$ water bath for $15 \mathrm{~min}$.

4. Add $5 \mu$ glassmilk. Add $1 \mu$ l glassmilk for every $1 \mu \mathrm{g}$ of DNA over $5 \mu \mathrm{g}$. Be sure to vortex glassmilk thoroughly before adding to DNA.

5. Place tubes on ice for $30 \mathrm{~min}$. Mix by inversion every $3 \mathrm{~min}$.

6. Pellet glassmilk in centrifuge $13 \mathrm{~K} \times \mathrm{g}$ for $5 \mathrm{sec}$. Remove supernatant.

7. Add $200 \mu$ l of New Wash solution and resuspend pellet via brief vortex.

8. Pellet glassmilk in centrifuge $13 \mathrm{~K} \times \mathrm{g}$ for $5 \mathrm{sec}$. Remove supernatant.

9. Repeat steps 7 and 8 two more times.

10. After final wash and supernatant removal, dry products in vacuum at med. heat for 5-10 min.

11. Elute DNA in $20 \mu l$ of sterile water. Tap tube with finger to mix. Place tube in $37^{\circ} \mathrm{C}$ water bath for $10 \mathrm{~min}$ to dissolve DNA.

12. Spin tube in table centrifuge for $5 \mathrm{sec}$.

13. Remove and save supernatant-pipet into new tube.

14. Repeat steps 11-13.

15. Dry down $40 \mu$ of new product in vacuum at med. heat for $15-25 \mathrm{~min}$.

16. Resuspend product in $11 \mu$ sterile water. Tap tube with finger to mix.

17. Elute DNA in $37^{\circ} \mathrm{C}$ water bath for $15 \mathrm{~min}$.

18. Store products in cold room until ready to sequence. 
(B). DOUBLE-STRANDED SEQUENCING PROTOCOL (from Wayne lab protocol).

1. Make Chase solution, premix and label mix. Make enough of each mix for the number of reactions +1 (to correct for overpipeting). Make separate premix for primer to sequence in both directions. Keep mixes on ice.

Premix-per $r \times n$.

$1.25 \mu$ primer

$2 \mu l 5 X r \times n$. buffer

$0.75 \mu \mathrm{l}$ DMSO

$0.65 \mu$ sterile water
Label mix-pre rxn.

$1 \mu \mathrm{DTT}$

1 Il 1:20 label mix

$1.00 \mu$ l sterile water

$0.35 \mu \mathrm{I}$ DMSO
Chase soln. $(100 \mu l)$

$64 \mu$ sterile water

$20 \mu \mathrm{l}$ dNTPS

$10 \mu \mathrm{I}$ DMSO

$6 \mu l 5 X$ rxn. buffer

2. Label microtiter plate as follows: GATC/GATC for each sample Add $2.5 \mu \mathrm{lddNTP}$ to corresponding wells and cover.

3. Label $0.65 \mathrm{ml}$ eppendorf tubes with sample numbers. For each sample, label one tube "L" for light strand and one "H" for heavy strand. Add $5 \mu \mathrm{INA}$ template and $4.65 \mu \mathrm{l}$ premix into corresponding tubes (e.g. add $5 \mu \mathrm{l}$ DNA and $4.65 \mu \mathrm{l}$ premix with "light" primer to "L" tube, and $5 \mu \mathrm{IDNA}$ and $4.65 \mu \mathrm{l}$ premix with "heavy" primer to "H" tube). Mix tubes well.

4. Heat eppendorf tubes in thermal cycler set at $94^{\circ} \mathrm{C}$. for $5 \mathrm{~min}$.

5. While tubes are heating, add ${ }^{35} \mathrm{~S}$-dATP to label mix $(0.50 \mu \mathrm{l}$ per rxn.)

6. Snap freeze tubes in mixture of dry ice and ethanol. Spin down in table centrifuge $5 \mathrm{sec}$. 
7. Add Sequenase to label mix $(0.15 \mu l$ per $r x n)$. Mix well.

8. Add $4 \mu$ l of label mix to each annealed template. Let reaction go for 3-4 min at room temperature.

9. Add $3 \mu$ l of reaction mix to each ddNTP and heat in $37^{\circ} \mathrm{C}$ water bath (do this step within 5 min. time frame).

10. Add $2 \mu \mathrm{l}$ Chase solution to each microtiter well and heat in $37^{\circ} \mathrm{C}$ water bath (do this step within 5 min. time frame).

11. Add $4 \mu$ Stop solution to each microtiter well. Mix well by shaking plate.

12. Store in $-20^{\circ} \mathrm{C}$ freezer for use the following day.

13. Before loading products into gel, heat plate on $94^{\circ} \mathrm{C}$ heating block for $3.5 \mathrm{~min}$.

14. Load $2.7 \mu$ of each ddNTP into sequencing gel. 